\title{
Evolução dos estudos sobre a ascendência da publicidade de marcas corporativas na formação da agenda pública de $2006-2018$
}

Evolution of studies on the ascendence of corporate brand advertising in the formation of public agenda. 2006 - 2018

Evolución de estudios del ascenso de la publicidad de marcas corporativas en la formación de la agenda pública. 2006 - 2018

DOI: https://doi.org/10.1590/1809-5844202125

\section{Eneus Trindade Barreto Filho ${ }^{1}$}

https://orcid.org/0000-0001-8231-4027

Daniel Dubosselard Zimmermann ${ }^{1}$

https://orcid.org/0000-0001-6827-206X

Karla de Melo Alves Meira1

https://orcid.org/0000-0002-2345-5927

${ }^{1}$ (Universidade de São Paulo, Escola de Comunicações e Artes, Programa de Pós-Graduação em Ciências da Comunicação. São Paulo - SP, Brasil).

\section{Resumo}

O artigo fornece uma análise longitudinal de artigos científicos em periódicos nacionais e internacionais, anais de congressos brasileiros, teses e dissertações que abordam a influência da publicidade de marcas corporativas na formação da agenda em fontes de publicidade, marketing e comunicação de 2006-2018. A problemática da pesquisa é a compreensão sobre o que há e quais são as características da literatura científica publicada sobre a influência da publicidade de marcas na formação da agenda pública. O objetivo é elucidar a direção e a progressão dessa temática no campo da publicidade e verificar a produção específica, seus aportes, métodos e conclusões. A partir de dados virtuais e leitura crítica, as produções selecionadas foram analisadas considerando: (1) segmento, (2) presença de teoria, (3) autores, (4) país de origem, (5) abordagens de pesquisa, (6) métodos, (7) aportes, argumentos e conclusões. Os resultados mostram que há o reconhecimento de que a publicidade interfere na agenda pública, mas não trazem aportes concretos para a comprovação dos modos destas interferências.

Palavras-chave: Levantamento sistemático longitudinal. Agenda-Setting. Comunicação. Publicidade. Marcas corporativas. 


\begin{abstract}
The article provides a longitudinal analysis of scientific articles in national and international journals, Brazilian congresses annals, dissertations, and theses that address the influence of corporate brand advertising on the formation of the 2006-2018 agenda in advertising, marketing, and communication sources. The research problem is the understanding of what there is and what are the characteristics of the scientific literature published on the influence of brand advertising on the public agenda's formation. The objective is to elucidate this theme's direction and progression in the field of advertising and to verify the specific production, its contributions, methods, and conclusions. From virtual data and critical reading, the selected productions were analyzed considering: (1) segment, (2) presence of theory, (3) authors, (4) country of origin, (5) research approaches, (6) methods, (7) contributions, arguments, and conclusions. The results show that there is a recognition that advertising interferes with the public agenda, but they do not bring concrete contributions to prove these interferences' modes.
\end{abstract}

Keywords: Longitudinal systematic survey. Agenda-Setting. Communication. Advertising. Corporate brands.

\title{
Resumen
}

El artículo proporciona un análisis longitudinal de artículos científicos en revistas nacionales e internacionales, anales de congresos brasileños, tesis y disertaciones que abordan la influencia de la publicidad de marca corporativa en la formación de la agenda en fuentes de publicidad, marketing y comunicación desde 2006-2018. El problema de la investigación es la comprensión de qué es y cuáles son las características de la literatura científica publicada sobre la influencia de la publicidad de marca en la formación de la agenda pública. El objetivo es dilucidar la dirección y la progresión de este tema en el campo de la publicidad y verificar la producción específica, sus contribuciones, métodos y conclusiones. A partir de datos virtuales y lectura crítica, las producciones seleccionadas se analizaron considerando: (1) segmento, (2) presencia de teoría, (3) autores, (4) país de origen, (5) enfoques de investigación, (6) métodos, (7) contribuciones, argumentos y conclusiones. Los resultados muestran que hay un reconocimiento de que la publicidad interfiere en la agenda pública, pero no aporta contribuciones concretas para probar los modos de estas interferencias.

Palabras claves: Investigación sistemática longitudinal. Agenda-Setting. Comunicación. Publicidad. Marcas corporativas.

\section{Introdução}

A hipótese do Agenda-Setting ou agendamento é uma teoria de comunicação formulada pelos norte-americanos Maxwell E. McCombs e Donald L. Shaw na década de 1970 e trata da relação entre a ênfase dada a um conteúdo nos meios de comunicação e a inclusão deste conteúdo nas prioridades do público. Tradicionalmente, quando se refere a 
agendamento, parte-se dos estudos de opinião pública ${ }^{1}$, os quais apontam para um modelo específico de construção da opinião pública que pressupõe o Newsmaking (HABERMAS, 1984, BARROS FILHO, 2003, TRAQUINA, 2000), que refere-se a selecionar e direcionar a agenda pública por meio de discursos que representem a "opinião dominante" como sendo o ponto de partida para tal processo e que se completa com a Hipótese do Agenda-Setting (McCOMBS; SHAW, 1972, BARROS FILHO, 2003, LIPPMANN, 2010).

De acordo com a hipótese, "a mídia, pela seleção, disposição e incidência de suas notícias, vem determinar os temas sobre os quais o público falará e discutirá” (BARROS FILHO, 2003, p. 169). Assim, nesses modelos, se traz o jornalista como responsável por selecionar aquilo que estará na agenda midiática (gatekeeping) e, por consequência, a notícia é a única forma de um tema, assunto, dado ou fato transformar-se, ou não, em alvo do debate público (agenda pública), logo, naquilo que será agendado. Isto porque o modelo de newsmaking está centrado no conceito de que o fato jornalístico é que se torna notícia, portanto, sendo o jornalista responsável por selecioná-la.

No entanto, para Da Viá (1983) e Watson (2008), o modelo proposto por McCombs e Shaw é questionável, já que os media propõem o que deve ser discutido ao selecionarem o que estará na agenda dos meios. Todavia, são os receptores mediados pelas características socioculturais, assim como por suas competências de recepção, que selecionarão o que será debatido na agenda pública com base em seus valores.

Não obstante, dados da Associação Brasileira de Imprensa - ABI (2016) e da Associação Brasileira das Agências de Comunicação - Abracom (2016), divulgados no Anuário da Comunicação Corporativa 2016, afirmam que aproximadamente 89\% das notícias publicadas nos veículos tradicionais são frutos de assessorias de comunicação, portanto, do esforço das organizações por meio de relações públicas e assessorias de imprensa e não produção dos próprios veículos. Assim, podemos pressupor que ações da publicidade de marcas corporativas são capazes também de agendar temas e valores sociais.

A suspeita é de que o agendamento se sucede diariamente, uma vez que a mídia mostra, esclarece, retoma informações, destacando, reduzindo ou mesmo omitindo em suas emissões. "O público ora procura, ora é alcançado por mensagens que visam entreter, informar, vender, induzir a posicionamentos, causar identificações” (ERNESTO, 2010, p. 69). Por meio dos interesses das pesquisas comuns dos autores deste artigo, iniciou-se em 2018 uma perspectiva de compreensão sobre como a publicidade de marcas corporativas também funciona na lógica do Agenda-Setting, cujos valores e temáticas sejam geradores ou operem na criação de filtros que, pela evidência da circulação midiática, demonstram novas articulações dos conceitos de gatekeeping e gatewatching, que são aplicados ao consumo como maneira de modelizar e instituir a lógica midiatizadora das marcas. Próximos a esta perspectiva proposta, registram-se os trabalhos de Trindade e Augusto Jr. (2015) e Mota e

1 Os estudos da Opinião Pública na América Hispânica são chamados de Demoscopia e no Brasil de Teorias da Opinião Pública. 
Batista (2014), que fazem reflexões semelhantes a proposta deste artigo e que servem de inspiração à pesquisa aqui realizada.

Então, com base no problema de pesquisa, busca-se a compreensão sobre o que há e quais são as características da literatura científica publicada sobre a influência da publicidade de marcas na formação da agenda pública, tendo como objetivos elucidar a direção e a progressão dessa temática no campo da Publicidade e verificar a produção específica, seus aportes, métodos e conclusões. Assim como investigar e descrever se existem pesquisas e, principalmente, artigos científicos que corroborem a ideia da publicidade de marcas corporativas como influenciadora na formação da agenda e, assim, poder afirmar se essa suposição foi testada e/ou amplamente discutida para alicerçar pesquisas futuras.

Vale salientar que este artigo é resultado da confluência de interesses e resultados partilhados das pesquisas do projeto-mãe Tendências da Pesquisa em Publicidade e Consumo no Brasil -2006 a 2018: a construção de um subcampo da pesquisa em comunicação, do primeiro autor, com financiamento CNPq, e do projeto de doutorado do segundo autor - A influência da Publicidade de Marcas na formação da Agenda Pública, ambas ações institucionalizadas de pesquisa aqui sintetizadas conjuntamente pela equipe autora deste artigo, que atua no GESC3 - Grupo de Estudos de Semiótica, Comunicação, Cultura e Consumo, USP/CNPq. Na sequência, são apresentados os métodos e resultados da pesquisa em detalhes.

\section{Métodos de Pesquisa}

O corpus de observação e análise foi delimitado aos trabalhos publicados nas revistas científicas e nos anais eletrônicos disponibilizados na internet e publicados no período compreendido entre 2006 e 2018 por mais de 70 periódicos nacionais e internacionais dos segmentos de marketing, comunicação e publicidade, e também anais dos principais congressos científicos nacionais na área de Comunicação (Compós - Encontro Nacional de Programas de Pós-Graduação em Comunicação, Pró-Pesq PP - Encontro Nacional de Pesquisadores em Publicidade e Propaganda, Intercom - Congresso Brasileiro de Ciências da Comunicação e Abrapcorp - Congresso da Associação Brasileira de Pesquisadores em Comunicação Organizacional e Relações Públicas) e do banco de teses da Plataforma Sucupira (Capes), mapeando o estado do conhecimento sobre a pesquisa acadêmica na influência da publicidade de marcas corporativas pela agenda.

Optou-se pela metodologia da pesquisa bibliográfica, que consiste no:

[...] planejamento global inicial de qualquer trabalho de pesquisa que vai desde a identificação, localização e obtenção de qualquer bibliografia pertinente ao assunto, a apresentação de um texto sistematizado (STUMPF, 2009, p. 51). 
A análise com base secundária foi realizada por meio de coleta documental e de conteúdo, já que de acordo com Covaleski (2017, p. 2):

[...] a metodologia de tratamento dos dados pode ser entendida como híbrida, situada entre o formalismo estatístico e a análise quantitativa, permitindo, assim, a verificação com requisitos de sistematicidade e confiabilidade, constituindo-se investigação que, também, é qualitativa, ao observar o teor e o contexto do material analisado.

Para estudar o conteúdo científico do campo da Comunicação, decidiu-se pelo levantamento bibliográfico sistemático, ou seja, por mapear o estado da arte deste segmento selecionado. Cervo e Bervian (2002) afirmam que a pesquisa bibliográfica constitui o procedimento básico pelos quais se busca o domínio do estado da arte sobre determinado tema e compõe parte da pesquisa descritiva quando é feita com o intuito de recolher informações e conhecimentos prévios acerca de algum tema que se deseje pesquisar.

O levantamento sistemático do ponto de discussão em que esse campo de estudo se encontra (estado da arte) é fundamental para justificar a relevância da pesquisa que se pretende realizar, frente a alguma lacuna, ou controvérsia, ou situação ainda não testada, ou complexidade ainda não resolvida nesse campo de estudo. (SANTAELLA, 2014, p. 1-2).

Já o estado do conhecimento vai além do estado da arte e busca verificar os percursos teóricos, metodológicos e outros que orientem o estudo de uma dada temática nos modos de monitorar o pensar sugerido pelos sujeitos do campo sobre marcas, publicidade e agenda-setting.

Pode-se utilizar a técnica de análise de conteúdo para o estudo de obras, objetivando desvendar a temática dos documentos (RICHARDSON, 2007) e, ainda, de acordo com Sampaio (2007), a revisão sistemática é um tipo de pesquisa que utiliza como fonte de dados a literatura sobre determinado tema. Este gênero de análise proporciona um resumo das evidências relativas a itens específicos, com a utilização de métodos explícitos e sistematizados para a busca, para avaliação crítica e para a síntese da informação pretendida. Conforme o autor, as revisões sistemáticas são desenhadas para serem metódicas e passíveis de reprodução. Esse tipo de estudo serve para nortear o desenvolvimento de projetos, indicando novos rumos para futuras investigações e identificando quais métodos de pesquisa foram utilizados em uma área.

O desejo primeiro desta pesquisa foi o de jogar luz sobre a progressão e direção do agenda-setting associado ao contexto das marcas corporativas, no campo de estudos acadêmicos da Publicidade e Propaganda, usando como inspiração e modelo o artigo de 
Yale e Gilly (1988) acerca da identificação das tendências da pesquisa publicitária, que, considerando suas implicações em outros campos de estudo, buscou compreender o rumo que editores de publicações, comentaristas e pesquisadores estavam tomando por meio da identificação dos assuntos pesquisados em maior e em menor escala, bem como a ascensão e ou queda de outros tópicos.

A partir da ideia do modelo de Yale e Gilly (1988) e Kim et al. (2014), decidiu-se por uma análise longitudinal para investigar e identificar dentro da produção científica nacional e internacional dos últimos 12 anos (2006 a 2018) quais delas abordavam a influência da publicidade de marcas corporativas na formação da agenda dos meios e da agenda pública. O delineamento longitudinal é aquele no qual existe uma sequência temporal em que a mesma amostra é medida diversas vezes ao longo do tempo e suas análises envolvem comparação dos dados entre os períodos investigados, sendo geralmente compostas por longos períodos de tempo.

Quanto maior o número de aspectos estudados, mais precisa será a análise do objeto de estudo. Rajulton (2001), tendo como foco o progresso ou a mudança de determinado fator, relata que a pesquisa longitudinal tem por objetivos obter a natureza e padrões de mudanças, identificação de similaridades e/ou diferenças e analisar inter-relações entre mudanças assinaladas.

A opção por essa metodologia se justifica pela variedade de enfoques teóricos, métodos e objetos desenvolvidos no eixo da comunicação, publicidade e marketing, sendo, desta maneira, possível responder ao problema de pesquisa e atingir os objetivos de forma consistente e robusta.

\section{Trajetória da Pesquisa}

Pesquisa-se, assim, a relação entre agendamento, publicidade e marcas corporativas, a partir de levantamento sistemático dos periódicos publicados, alguns congressos brasileiros importantes da área e teses e dissertações do Brasil, no período de 2006 a 2018. E, através da análise longitudinal de conteúdo, o estudo exploratório foi realizado por meio de análise de indicadores por título, por palavras-chave e conteúdo, considerando para a pesquisa: em português, os termos = Agenda (Agenda-Setting, Agenda dos Meios, Agendamento, Agenda Pública e Agenda), Marcas Corporativas, Publicidade e Propaganda; e, em inglês, os termos = Agenda, Agenda Setting, Corporate Brand, Corporate Branding, Advertising.

Contemplou-se os artigos publicados por mais de 450 periódicos nacionais e internacionais - dos quais 73 indicaram o conteúdo desejado - incluindo revistas científicas nacionais e internacionais dos segmentos de marketing e negócios, comunicação e publicidade 
e também os anais dos principais congressos científicos nacionais na área de Comunicação (especificamente os eventos da Compós - Encontro Nacional de Programas de Pós-Graduação em Comunicação, Pró-Pesq PP - Encontro Nacional de Pesquisadores em Publicidade e Propaganda, Intercom - Congresso Brasileiro de Ciências da Comunicação e Abrapcorp Congresso da Associação Brasileira de Pesquisadores em Comunicação Organizacional e Relações Públicas) ao longo de 12 anos, bem como dissertações e teses. Utilizou-se as Bases de Dados Communication \& Mass Media Complete, Academic Search Premier, Business Source Complete, Portal Periódicos Capes e plataforma Sucupira para incluir o conteúdo completo nacional e internacional desejado. De acordo com Yale e Gilly (2014), o registro público da pesquisa publicitária está refletido de forma esmagadora nas revistas dos campos de publicidade, marketing e comunicação.

O primeiro critério de busca era a palavra Agenda-Setting no título ou nas palavraschave. Em seguida, para refinar a busca, foram utilizados separadamente as expressões “Marca Corporativa”, “Publicidade” e "Propaganda”, daí então os artigos coletados passaram a ser verificados utilizando as expressões somadas e, finalmente, aqueles que acusaram a presença de todas foram lidos para verificação de conteúdo direto ou indireto que pudesse subsidiar e referenciar a pesquisa. Após as leituras e a redução dos artigos, foram identificados apenas aqueles que estivessem efetivamente abordando a influência da publicidade na formação da agenda.

Por se tratar da segunda fase da pesquisa em desenvolvimento, esse artigo, que amplia o levantamento inicial, conservou-se também na detecção da relação entre os termos já descritos em periódicos científicos e anais de congressos que trazem artigos sobre o campo da Publicidade e Propaganda, assim como dissertações e teses. Este escopo foi determinado por dois motivos: 1) levantamento da existência destas categorias, que compõem a estrutura textual dos artigos, com potencial para futuras relações entre si nas fases seguintes da pesquisa; e 2) investigação da dinâmica dos elementos que compreendem as categorias definidas nos trabalhos publicados no intervalo de 12 anos ininterruptos.

Periódicos nacionais e internacionais que apresentaram artigos sobre a temática após a primeira e segunda filtragem: 
Quadro 1 - Periódicos Identificados por Segmento de 2006-2018

\begin{tabular}{|c|c|c|}
\hline Segmento & Journals/Periódicos Científicos & $\begin{array}{l}\text { Total por } \\
\text { Segmento }\end{array}$ \\
\hline $\begin{array}{l}\text { Publicidade } \\
\text { Propaganda }\end{array}$ & $\begin{array}{l}\text { China Media Report Overseas, International Journal of Advertising, Journal of Advertising, Journal of Advertising Research, } \\
\text { Journal of Current Issues \& Research in Advertising e Journal of Promotion Management }\end{array}$ & 6 \\
\hline Marketing e Negócios & $\begin{array}{l}\text { Academy of Management Review, Business Strategy and the Environment, Bussiness and Society, DSI Essays Series, European } \\
\text { Journal of Marketing, Institutional Repository -WU Vienna University of Economics and Business, Journal of Brand } \\
\text { Management, Journal of Business Ethics, Journal of Communication Management, Journal of Consumer Research, Journal of } \\
\text { Management Studies, Journal of Marketing, Journal of Marketing Communications, Journal of Marketing Research, Journal of } \\
\text { Political Marketing, Journal of Psychology \& Marketing, Journal of Public Policy \& Marketing, Journal of the Academy of } \\
\text { Marketing Science, Management Decision, Odete School of Business Publications, RAE-Revista de Administração de Empresas } \\
\text { (Brasil), Reputation Management, Research of Midlands State University, Review of Integrative Bussiness Economic Research, } \\
\text { South East Asia Journal of Contemporary Business, Economics and Law, SSRN Electronic Journal, The Journal of Corporate } \\
\text { Citizenship, The Marketing Review }\end{array}$ & 28 \\
\hline \multirow[t]{2}{*}{ Comunicação } & $\begin{array}{l}\text { Canadian Journal of Communication, Communication Today, Communication, Culture \& Critique, Comumicatio - South } \\
\text { Africa, Revista Comunicação, Midia e Consumo (Brasil), Comunicación y Sociedad (Espanha), Corporate Communications: an } \\
\text { International Journal, Corporate Reputation Review, Cuadernos de Información - Chile, Florida Communication Journal, } \\
\text { Intercultural Communication Studies, International Communication Division - AEJMC, International Journal of } \\
\text { Communication, International Journal of Disclosure and Governance, International Journal of Scientific Research, International } \\
\text { Journal of Sport Communication, Journal of Applied Communications, Journal of Health Communication, Journal of Magazine } \\
\text { \& New Media Research, Journal of Media Research, Journal of Public Relations Research, Media International Australia, } \\
\text { Nordicom Review, Revista Organicom (Brasil), Revista Comunicação Midiática (Brasil), Revista Comunicação e Sociedade } \\
\text { (Portugal), Popular Communication, Public Relations Inquiry, Revista de Estudios de Comunicacion ZER (Espanha), Revista } \\
\text { FAMECOS - Midia, Cultura e Tecnologia (Brasil), Midiaticom (Brasil), Revista Mexicana de Comunicacion (México), Science } \\
\text { Communication, Semantic Scholar, Stamford Journal of Media, Communication and Culture, The International Journal on } \\
\text { Media Management, Westminster Papers in Communication \& Culture e Women's Studies in Communication }\end{array}$ & 39 \\
\hline & Total Geral & 73 \\
\hline
\end{tabular}

Fonte: autoproduzido pelos autores, 2019.

\section{Resultados}

A problemática que se espera debater aqui caminha para o esclarecimento de quais são as contribuições que a pesquisa em comunicação, publicidade e marketing tem realizado no mundo, nos 12 últimos anos, sobre a intersecção dos temas Agenda-Setting, Marcas Corporativas e Publicidade e se, em algum espectro, esses estudos permeiam a influência da publicidade de marcas corporativas na agenda.

Verificou-se que uma gama de periódicos de 2006 a 2018 publicaram artigos nos quais a agenda, a publicidade e as marcas corporativas se relacionam de alguma forma, assim como nota-se a concentração nos periódicos e congressos do segmento de comunicação, seguido pela área de marketing e negócios e, só então, os específicos sobre publicidade e propaganda, ao menos do ponto de vista quantitativo. 
Ainda foi possível registrar uma tendência de artigos sobre agenda, marcas e publicidade no European Journal of Marketing (10), Journal of Marketing Communications (8) e no International Journal of Advertising (5) e, no caso do Brasil, mais especificamente nos congressos e encontros científicos Intercom - Congresso Brasileiro de Ciências da Comunicação (42) e Pró-Pesq PP - Encontro Nacional de Pesquisadores em Publicidade e Propaganda (15).

Quadro 2 - Relação de Teses e Dissertações que abordam os termos de 2006-2018

\begin{tabular}{l|l|c|l|l}
\hline \multicolumn{4}{c}{ País } & \multicolumn{2}{c}{ Região } & Número & \multicolumn{1}{c}{ Instituição de Ensino Superior } \\
\hline África do Sul & África & 1 & Stellenbosch Uiversity \\
\hline Brasil & América Latina & 1 & Universidade Federal de Santa Catarina \\
\hline Brasil & América Latina & 1 & Universidade de São Paulo \\
\hline Brasil & América Latina & 1 & Universidade de Sorocaba \\
\hline Brasil & América Latina & 1 & Universidade Metodista de São Paulo \\
\hline Brasil & América Latina & 1 & Universidade de Brasília \\
\hline Brasil & América Latina & 1 & Universidade Federal do Rio Grande do Sul \\
\hline Coréia do Sul & Ásia & 2 & KAIST College of Business \\
\hline Espanha & Europa & 1 & Universidad de Murcia \\
\hline Espanha & Europa & 1 & Universidad Complutense de Madrid \\
\hline Estados Unidos & América do Norte & 1 & Syracuse University \\
\hline Estados Unidos & América do Norte & 1 & University ofFlorida \\
\hline Grécia & Europa & 1 & University of Nicosia \\
\hline Holanda & Europa & 1 & University of Leiden \\
\hline Malásia & Ásia & 1 & Othman Yeop Abdullah - Universiti Utara \\
\hline México & América Latina & 1 & National University of Quilmes \\
\hline Portugal & Europa & 1 & Escola Superior de Educação de Viseu \\
\hline Portugal & Europa & 1 & Universidade do Minho \\
\hline Reino Unido & Europa & 1 & Brunel Business School \\
\hline Reino Unido & Europa & 1 & The University of Bradford \\
\hline Suíça & Europa & 1 & University of Lausanne \\
\hline
\end{tabular}

Fonte: autoproduzido pelos autores, 2019.

No que se refere às teses e dissertações (22), nota-se que não há uma grande produção e mesmo com o Brasil apresentando a maior quantidade delas, não podemos afirmar que se destaque no estudo do tema.

Como já mencionado, para restringir a pesquisa e se chegar a resultados mais efetivos, a busca foi realizada como descrito no Quadro 3, onde verifica-se que, na parte que se refere a pesquisa, por meio de base de dados virtuais e o auxílio do programa Foxit 
Reader, foi possível filtrar e dimensionar em 203 produções científicas, as quais foram lidas e analisadas.

Quadro 3 - Relação entre termos de busca e quantidade de artigos científicos identificados nas bases de pesquisa de 2006-2018

\begin{tabular}{|l|c|}
\hline \multicolumn{1}{|c|}{ Termoção entre termos de busca e quantidade de artigos científicos identificados nas bases de pesquisa de 2006-2018 } \\
\hline \multicolumn{1}{|c|}{$\begin{array}{c}\text { Artigos } \\
\text { Científicos }\end{array}$} \\
\hline Agenda-Setting (Agenda Setting, Agendamento, Agenda, Agenda dos Meios, Agenda Pública) & 5.623 .845 \\
\hline $\begin{array}{c}\text { Agenda-Setting (Agenda Setting, Agendamento, Agenda, Agenda dos Meios, Agenda Pública) + } \\
\text { Publicidade Propaganda (Advertising) }\end{array}$ & 99.350 \\
\hline $\begin{array}{c}\text { Agenda-Setting (Agenda Setting, Agendamento, Agenda, Agenda dos Meios, Agenda Pública) + Marcas } \\
\text { Corporativas (Corporate Brand, Corporate Branding) }\end{array}$ & 4.371 \\
\hline $\begin{array}{c}\text { Agenda-Setting (Agenda Setting, Agendamento, Agenda, Agenda dos Meios, Agenda Pública) + } \\
\text { Publicidade Propaganda (Advertising) + Marcas Corporativas (Corporate Brand, Corporate Branding) }\end{array}$ & 492 \\
\hline $\begin{array}{c}\text { Artigos que nas buscas eletrônicas congregaram as 3 expressöes nas palavras-chave, sumário elou } \\
\text { conteúdo }\end{array}$ & 203 \\
\hline $\begin{array}{c}\text { Artigos que após a leiturae o cruzamento dos itens pesquisados continham diretaou indiretamente } \\
\text { relação com as } 3 \text { expressões }\end{array}$ & 19 \\
\hline $\begin{array}{c}\text { A Influência da Publicidade de Marcas Corporativas na Formação da Agenda Pública(The Influence of } \\
\text { Corporate Brand Advertising on Public Agenda Formation) }\end{array}$ & $\mathbf{2}$ \\
\hline
\end{tabular}

Fonte: autoproduzido pelos autores, 2019.

Antes da leitura detalhada e do mapeamento da produção que efetivamente fosse relacionado à pesquisa, procedeu-se a identificação da evolução da produção ano a ano, considerando as 203 produções e todas as fontes, onde fica claro a oscilação do interesse pela temática, assim como o ano onde ocorreu um boom foi 2009 com 28 produções e voltando a crescer em 2014 com 18 produções.

Já em relação especificamente a comparação entre os quatro principais eventos científicos que tratam do estudo da comunicação e/ou da publicidade propaganda, foi possível verificar que há uma predominância do Intercom com 42 produções ao longo de 12 anos e os demais, Pró-Pesq PP, Compós - Encontro Anual dos Programas de Pós-Graduação em Comunicação e Abrapcorp -Congresso Brasileiro de Comunicação Corporativa apresentando uma diferença pouco relevante entre si, no entanto, o Pró-Pesq PP vem crescendo em produção sobre o tema em relação aos demais.

Quanto à distribuição longitudinal da produção científica (Quadro 4), foi possível verificar que os periódicos e os anais de congressos científicos do segmento de comunicação foi onde se concentrou, ao longo dos últimos 12 anos, 50,3\% da produção sobre a temática, seguido do segmento de marketing e negócios, com 27,1\% e o segmento de publicidade ficando apenas com 11,8\%. No caso das teses e dissertações, as de marketing e negócios aparecem na frente com 4,9\%, comunicação com 4,4\% e publicidade com 1,5\%. 
Quadro 4 - Distribuição Longitudinal da Produção Científica Interseccional - 2006-2018

\begin{tabular}{|c|c|c|c|c|c|c|c|c|c|c|c|c|c|c|c|c|}
\hline \multicolumn{17}{|c|}{ Distribuição Longitudinal da Produção Cientifica Interseccional: Agenda-Setting, Publicidade e Marcas (2006 - 2018) } \\
\hline $\begin{array}{l}\text { Segmento da } \\
\text { Fonte }\end{array}$ & Tipo de Fonte & ๕ัँ & हूँ & ङ్ & ฏ્ले & 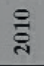 & हี & ีำ & $\stackrel{\text { m }}{\pi}$ & ت্ & लू & ఊัก & है & $\stackrel{\infty}{\tilde{\pi}}$ & $\stackrel{5}{\circ}$ & हू \\
\hline \multirow{3}{*}{ Publicidade } & $\begin{array}{l}\text { Artigos em } \\
\text { periódicos }\end{array}$ & 0 & 0 & $\mathbf{0}$ & 2 & 2 & 1 & 0 & 2 & 5 & 2 & 1 & 0 & 0 & 15 & 7,4 \\
\hline & Artigos em anais & 0 & 0 & 0 & 0 & 0 & 4 & 2 & 0 & 0 & 0 & 1 & 0 & 2 & 9 & 4,4 \\
\hline & $\begin{array}{c}\text { Dissertações e/ou } \\
\text { teses }\end{array}$ & 0 & 0 & 0 & 1 & 1 & 0 & 0 & 0 & 1 & 0 & 0 & 0 & 0 & 3 & 1,5 \\
\hline \multirow{3}{*}{$\begin{array}{l}\text { Marketing e } \\
\text { Negócios }\end{array}$} & $\begin{array}{l}\text { Artigos em } \\
\text { periódicos }\end{array}$ & 4 & 3 & 3 & 8 & 4 & 2 & 4 & 4 & 6 & 6 & 3 & 0 & 1 & 48 & 23,7 \\
\hline & Artigos $\mathrm{em}$ anais & 2 & 0 & 0 & 0 & 0 & 1 & 0 & 1 & 0 & 0 & 0 & 0 & 3 & 7 & 3,4 \\
\hline & $\begin{array}{c}\text { Dissertações e/ou } \\
\text { teses }\end{array}$ & 0 & 0 & 1 & 0 & 0 & 1 & 0 & 2 & 1 & 1 & 1 & 3 & 0 & 10 & 4,9 \\
\hline \multirow{5}{*}{ Comunicação } & $\begin{array}{l}\text { Artigos em } \\
\text { periódicos }\end{array}$ & 3 & 4 & 3 & 6 & 3 & 3 & 4 & 3 & 4 & 3 & 5 & 6 & 1 & 48 & 23,7 \\
\hline & Artigos em anais & 8 & 7 & 6 & 11 & 7 & 4 & 1 & 4 & 0 & 4 & 0 & 0 & 2 & 54 & 26,6 \\
\hline & $\begin{array}{c}\text { Dissertações e/ou } \\
\text { teses }\end{array}$ & 0 & 2 & 1 & 0 & 1 & 1 & 2 & 0 & 1 & 0 & 1 & 0 & 0 & 9 & 4,4 \\
\hline & Total & 17 & 16 & 14 & 28 & 18 & 17 & 13 & 16 & 18 & 16 & 12 & 9 & 9 & 203 & 100 \\
\hline & Total(\%) & 8,4 & 7,9 & 6,9 & 13,8 & 8,8 & 8,4 & 6,4 & 7,9 & 8,8 & 7,9 & 6 & 4,4 & 4,4 & 100 & \\
\hline
\end{tabular}

Fonte: autoproduzido pelos autores, 2019.

Após essa análise, foi procedida a leitura comparativa das 203 produções científicas, onde se verificou alguns aspectos interessantes, tais como, a inconsistência entre a relação do resumo, palavras-chave e conteúdo das pesquisas, pois em vários casos o resumo trazia terminologias que não se repetiam nas palavras-chave e depois no texto eram inexpressivos. No caso da produção brasileira, esse problema é mais relevante, pois aproximadamente $60 \%$ dos trabalhos não faziam relação entre esses três importantes itens de relatos científicos. Depreende-se que, no artigo científico, os itens básicos de título, resumo e, sobretudo, as palavras-chave facilitam o trabalho de indexação de um documento. A nomeação inadequada destes itens, simultaneamente a excessos e omissões, dificulta a indexação do assunto e sua localização por outros pesquisadores.

Após as leituras combinadas e comparadas, detectamos que apenas 19 artigos, em sua maioria provenientes de congressos científicos, relacionavam as três expressões. Porém, a expressão "marcas corporativas” não aparece claramente e, sim, no conteúdo desenvolvido. Destes, 12 são nacionais e sete internacionais, dos quais quatro estadunidenses e um chileno. Um dos artigos nacionais foi produzido em parceria com um pesquisador espanhol, assim como um dos estadunidenses foi produzido em conjunto com um pesquisador coreano.

Outro dado interessante é que, em relação à fonte, no Brasil todos são provenientes de eventos científicos, sendo Pró-Pesq PP (7), Intercom (4) e Compós (1). Diferente dos 
internacionais, onde cinco são de periódicos e apenas um é de um encontro científicoprofissional, mesmo assim tendo sido republicado em um periódico.

E diferente da primeira parte da análise, ocorreu uma inversão, pois o segmento predominante passou a ser publicidade (12), comunicação (5) e marketing e negócios (2), com destaque para a produção nos anos de 2011 e 2016.

Os autores brasileiros com o maior número de publicações são João Vicente Seno Ozawa, com seis artigos, Leandro Leonardo Batista com quatro artigos e Clóvis de Barros Filho com dois artigos, e os demais com apenas uma produção. Sendo metade dos artigos baseados em estudos de caso, seguido de revisão bibliográfica e entrevistas em profundidade.

Quanto ao conteúdo e a relação com a influência da publicidade de marcas corporativas na formação da agenda pública, pode-se perceber a partir dos 203 artigos preliminares que muitos autores apontam para a existência direta de uma relação, porém, sem nenhum estudo dirigido, pesquisa aplicada ou base teórica, são apenas inferências feitas com base em outras pesquisas.

No caso dos 19 artigos que abordam direta ou indiretamente essa temática, apenas dois são especificamente sobre a relação entre o Agenda-Setting e a Publicidade, porém apenas o artigo "Levantamento Sistemático Longitudinal dos Estudos Científicos sobre a Influência da Publicidade de Marcas Corporativas na Formação da Agenda de 2007-2017” de Zimmermann e Meira (2018) é o único que realmente trata também de marcas corporativas. O outro artigo diz que irá fazer esse estudo, mas, na verdade, não o faz e os demais apenas citam fatores que podem levar à formação da agenda. No entanto, há um consenso sobre a necessidade desse estudo.

[...] a hipótese do agenda setting é - quase exclusivamente - aplicada a produtos jornalísticos. Uma investigação sobre agendamento de uma temática publicitária seria bastante inédita. Existe uma óbvia relevância da publicidade como produto da indústria cultural veiculado pela mídia (SENO OZAWA; BARROS FILHO, 2008, p. 4).

Trindade e Augusto Junior (2015), ao tratarem dos aprofundamentos de aspectos conceituais entre as mediações culturais e a midiatização do consumo alimentar, abordam a questão das relações entre a publicidade e a formação da agenda, no entanto, sua proposta foca no consumo alimentar e não propriamente em marcas corporativas.

Consideramos que as megatendências do consumo alimentar, dadas em Madi et al. (2010), funcionam como uma espécie de agenda setting, cujos temas/valores são geradores ou atuam na criação de filtros que pela evidência da circulação midiática, digital sobretudo, mostrando novas articulações dos conceitos de gatekeeping e gatewatching aplicados ao consumo, como forma de modelizar e instituir a lógica midiatizadora das marcas de alimentos, enquadradas em tais tendências (TRINDADE; AUGUSTO JUNIOR, 2015, p. 1). 
Em consonância, Motta e Batista (2014) realizaram um artigo sobre influência da publicidade e do consumo na formação da opinião, objetivando resgatar os processos de gatekeeping e gatewatching como conceitos comuns ao universo jornalístico. Os autores indicaram, no artigo, as potencialidades dessa inserção e perspectiva nos estudos de mídia e consumo.

Já El Faro e Carrascoza (2015) desenvolveram um artigo que relaciona a publicidade com a teoria do Agenda-Setting, passando primeiro pelo estudo da informação no contexto da sociedade do espetáculo e consumo, e pelos recursos retóricos na comunicação. Entretanto, estabelecem essa relação por meio da criação de anúncios de oportunidade advindos das produções jornalísticas.

Boyle (2010), em sua pesquisa, propôs que a propaganda de um candidato poderia interferir na agenda pública a ponto de contra-agendar o mesmo na agenda midiática, favorecendo, então, o candidato por meio de notícias positivas. No entanto, este artigo não registrou nenhuma mudança da agenda midiática. Resultado este que foi atribuído ao desinteresse dos meios de comunicação de massa em relação ao candidato analisado.

Alp (2016) analisou casos de posicionamentos políticos e valores das sociedades pela perspectiva do agendamento por meio da publicidade, da propaganda e das relações públicas e também a forma como interferem no agendamento de campanhas eleitorais, e mesmo em períodos não-eleitorais, para construir uma opinião pública que represente a posição do grupo que a utiliza. Partindo daí, afirma que não há como desarticular a Teoria do AgendaSetting da Teoria da Espiral do Silêncio. Essa lógica se dá pelo princípio de que os seres humanos adotam o lado dos poderosos. Logo, o eleitor, ao acreditar que sua opinião está entre as opiniões menos dominantes, estará menos inclinado a expressá-la. Eventualmente, as opiniões que são consideradas dominantes ganharão mais importância e se tornarão ainda mais dominantes, enquanto opiniões alternativas diminuem ainda mais.

$\mathrm{O}$ autor ainda traz a perspectiva de que a imagem do mundo é desenvolvida e criada em grande parte pelos meios de comunicação de massa e, posteriormente, a mídia impõe às massas o que pensar sobre a imagem criada. Em outras palavras, o mundo a ser considerado e as questões a serem pensadas sobre este mundo e as formas de pensar são determinadas apenas por um punhado de pessoas. Então, na perspectiva do autor, o mundo criado pela mídia será adotado como uma opinião básica por partidos políticos e candidatos que pretendem se beneficiar dos valores sociais para construírem suas próprias realidades e, assim, influenciarem a agenda pública por meio da publicidade, da propaganda e das relações públicas (ALP, 2016).

No contexto político, ainda se identificou Kim et al. (2016) apontando para a publicidade como um dos condicionantes das agendas, ao tratar dos dois primeiros níveis de agendamento durante o processo eleitoral estadunidense em 2012. Analisam a intersecção entre a propaganda política, os noticiários e o Twitter. Neste artigo, os autores concluem que a publicidade se utiliza do framing (efeito de enquadramento) para enquadrar a realidade e, portanto, capaz de agendar esses “enquadramentos” como reais. 
De outro lado, Kaneva (2011) utiliza o exemplo dos Estados Unidos para constatar que uma "marca de nação" agenda por meio de notícias, publicidade, relações públicas, filmes e mídias sociais digitais, assim promovendo o debate sobre seus valores e, por consequência, construindo sua imagem como uma marca.

Verificou-se, ainda, que existe uma tendência a traçar o paralelo entre o agendamento por meio da publicidade de marcas com foco no digital. Sendo, então, os principais autores que relacionam a agenda com a publicidade e as relações públicas, mais especificamente no contexto digital, Esrock e Leichty (1998), os quais são os mais citados em periódicos internacionais de comunicação, publicidade e marketing sobre o tema. Mais recentemente, Guo (2012) também traz o tema, mas limita-se a relacionar a agenda nas mídias sociais digitais.

Hazaparu (2014) apresenta sua pesquisa sobre conceitos e perspectivas éticas na publicidade baseando-se na teoria do Agenda-Setting de McCombs e Shaw (1972) e no modelo tripolar das agendas de Watson (2008), utilizando como unidade de análise o “[...] caso de uma controversa campanha de publireportagens sobre um grande projeto mineiro em Roşia Montană, uma região histórica da Roménia” (HAZAPARU, 2014, p. 311). Para tanto, o autor dispensou abordagens clássicas sobre ética para propor uma análise contextual dos dilemas éticos.

Apesar de Hazaparu (2014) não ter utilizado nenhuma metodologia que testasse efetivamente os efeitos ou a recepção da publicidade na agenda, assim como entre seus objetivos não estivesse comprovar se a publicidade agenda temáticas ou se ela apenas reagenda temas que estão latentes ou quiescentes na sociedade, sua pesquisa parte do pressuposto de que a publicidade agenda e suas análises indicam que sim. Além disso, assim como Watson (2008), indica que existe na publicidade e nas relações públicas um fluxo similar ao do jornalismo no processo de seleção de temáticas que podem ou não ser agendadas, indicando que o comunicador seleciona temas pré-existentes com base nos valores da sociedade, os quais estão dormentes. Ou seja, para que um tema, assunto ou fato seja agendado, é necessário que esteja relacionado a um valor que já esteja presente na sociedade.

Esse raciocínio é facilmente explicado pelos estudos da psicologia sobre o processo de formação da memória (NOBRE; EDE, 2017) e o da atenção (MYERS, 2012), pois para que o receptor perceba e receba uma mensagem de forma consciente, é necessário primeiro a atenção, ou seja, que o receptor selecione a mensagem como prioridade diante de outros estímulos. Depois, que ele armazene a informação e, posteriormente, processe a mensagem, conectando-a a fatores preexistentes em sua memória, para só então adotar um posicionamento positivo ou negativo. Logo, entendendo que esse processo trata de como o ser humano constrói seu repertório, o que o torna capaz de estabelecer outras relações mais implexas, para qualquer comunicação, inclusive a publicidade, o receptor precisa conectar a mensagem recebida a fatores antecedentes em sua memória.

Hazaparu (2014) conclui seu estudo afirmando que, no caso descrito, a publicidade se utilizou de interações entre três agendas interessadas - corporativa, política e dos media -, numa tentativa de dominar a agenda pública, isso posto na premissa de que 
[...] a publicidade não é um tipo de comunicação bidirecional linear (das equipas de RP e publicidade das empresas em direção aos consumidores), mas um processo complexo, interativo e multifacetado, que necessita do contributo de muitos outros atores (organizações, cidadãos, média, sociedade civil, instituições regulamentares, etc.) para chegar ao "aspeto" final do produto de publireportagem. Apenas o mero facto de existir um número crescente de organismos de regulação a tentar delimitar o setor da publicidade constitui um forte indício da sua natureza interativa e da sua complexidade. Por conseguinte, a sua redução a perspectivas moralistas ou a pontos de vista extremistas que colocam a ênfase na bondade ou na maldade da publicidade evidencia uma compreensão redutora da natureza multidimensional da publicidade. (HAZAPARU, 2014, p. 312-313).

A proposta de agendamento feita por Watson (2008) não aparece em nossa pesquisa de forma direta, já que o texto em que trata do sistema publicitário como uma possibilidade de agendamento está no livro "Media Communication. An Introduction to Theory and Process", no entanto, o autor serve de referência em vários artigos. O que fica evidente no trabalho de Watson é a apresentação de um novo modelo, o “modelo tripolar das agendas”, que introduz as agendas políticas e corporativas, onde nessas a publicidade e as relações públicas são importantes no processo de inserção de temas, na tentativa de organizações e mesmo grupos políticos engendrarem e articularem a opinião pública em seu favor por meio da sobrecarga de informações.

Figura 1 - Modelo Tripolar das Agendas, de Watson

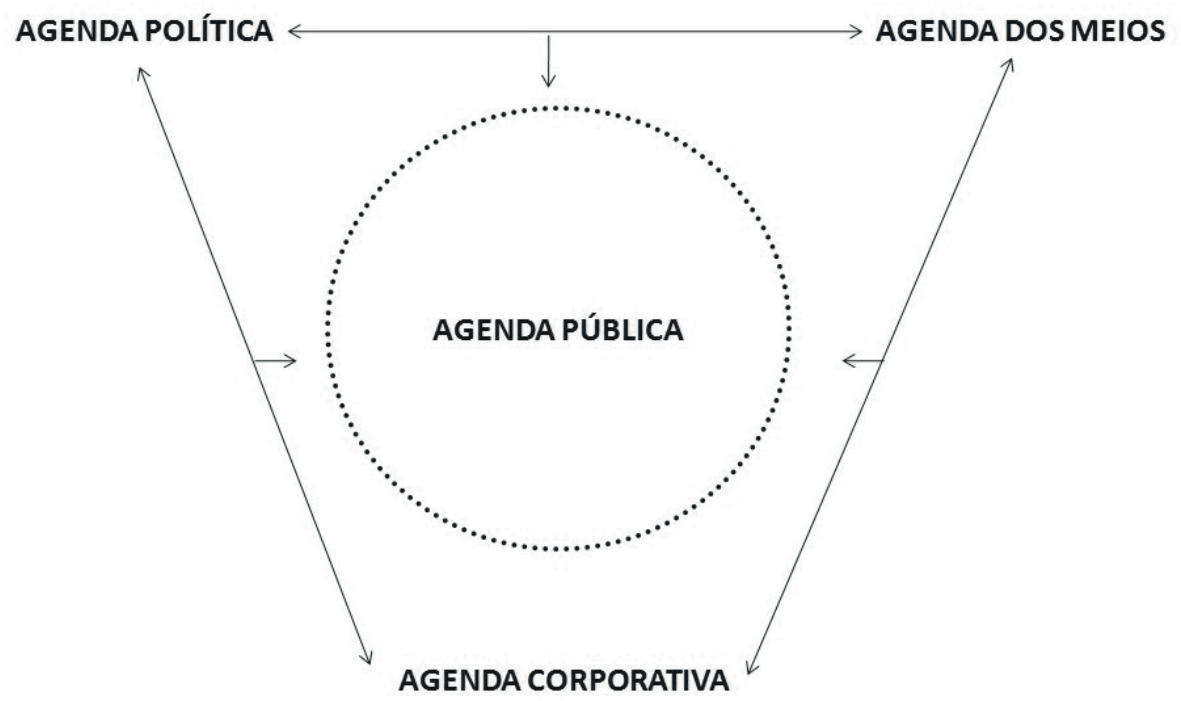

Fonte: Watson (2008) - adaptação dos autores. 
Outro aspecto importante sobre o modelo tripolar proposto por Watson (2008) diz respeito a inclusão da agenda das corporações, que dominam a vida contemporânea da sociedade de consumo. As organizações, então, por meio de publicidade, de relações públicas, de lobby e de assessoria de imprensa, irão promover seus interesses, alinhando a sua comunicação organizacional a temáticas já existentes. No caso da agenda dos meios as organizações, sempre estarão em concordância, principalmente por sua influência econômica sobre a mesma, porém, no caso da agenda política, elas podem estar alinhadas ou serem concorrentes, porém, sempre se associando a temas e valores que emanam do contexto sociocultural e de fatores preexistentes na sociedade para, então, ordenar as agendas públicas e influenciar a opinião pública.

Outros autores que também não apareceram nesta pesquisa, seja pela origem da publicação, pelo escopo da publicação ou mesmo ano da produção, mas que se considera importante citar, foram Rogers e Dearing (1988), que propõem a inserção da agenda política no esquema das agendas e que descrevem o agendamento como um processo interacional de influência entre a agenda pública, a agenda dos meios e a agenda política.

Figura 2 - Modelo do Processo Social das Agendas

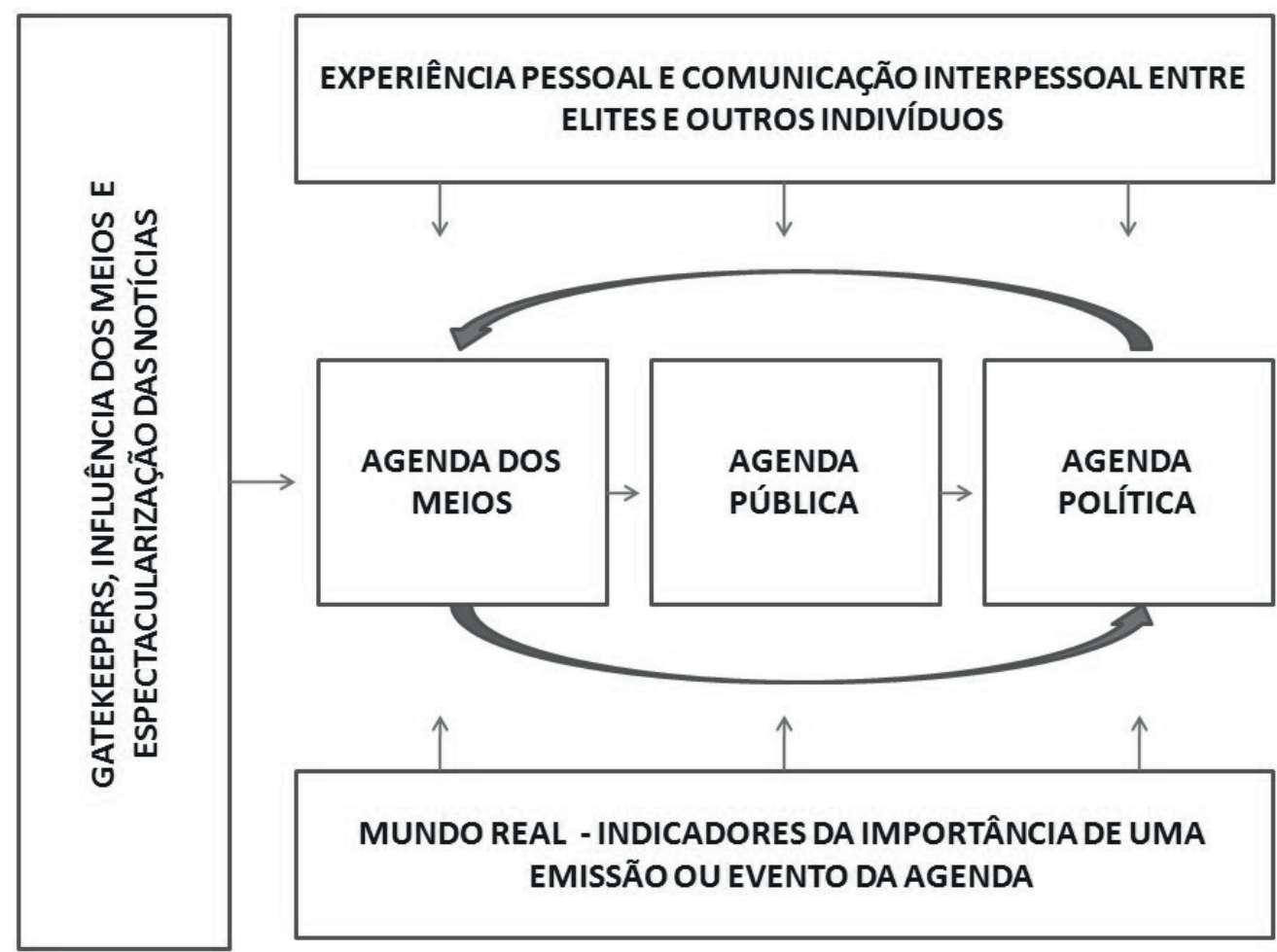

Fonte: Rogers e Dearing (1988) - adaptação dos autores. 
E, ainda, Albalawi e Sixsmith (2015) que, ao pesquisarem sobre as melhores práticas na promoção da saúde, onde a comunicação de risco é fundamental para a mudança de atitude, descreveram uma nova agenda em resposta à contribuição das mídias sociais digitais, alterando e adaptando os modelos de Rogers e Dearing (1988) e o de Watson (2008). A unidade de análise da pesquisa foram comunicações relacionadas à prevenção de acidentes de trânsito na Arábia Saudita, e estabeleceu uma relação entre efeitos e recepção por meio da análise da eficácia do Twitter. Apesar do trabalho ter sido desenvolvido na área de saúde pública, o artigo não só propõe esta nova agenda como trata da influência da publicidade no agendamento de causas.

Quanto à publicidade de marcas, corporativas inclusive, o que fica claro é que os autores acreditam que seu poder de agendamento se dá se a publicidade estiver calcada em valores da organização que dialoguem com os valores sociais.

Las marcas empezaron así a ampliar su área de actuación y además de en la esfera clásica del consumo las marcas pusieron su punto de mira en otros territorios: espectáculos, deportes, cultura, política etc. La publicidad fue uno de los caminos claves que posibilitó y posibilita la difusión y la comunicación de las marcas, apelando para ello cada día más a los valores de nuestra cultura. (VILAR; COVALESKI, 2017, p. 5).

Seja para reforçá-los ou combatê-los:

A publicidade contraintuitiva configura-se como uma ferramenta importante, na perspectiva dos estudos da comunicação, para a emergência de se provocar e ampliar na sociedade a formação de debates que influenciem o comportamento, a opinião, as avaliações e o modo de perceber as realidades de grupos minoritários; colaborando assim para a construção de um ambiente normativo social que desencoraje os efeitos reacionários da manifestação da ameaça dos estereótipos e do preconceito essencialista. (LEITE, 2012, p. 650).

Daí o foco no papel ativo do receptor da mídia, de um lado agindo como cidadão, ao provocar a accountability das empresas - na medida em que o cidadão seria responsável por cobrar das empresas um comportamento socialmente responsável - e, de outro lado, agindo como consumidor, tanto das empresas como da mídia, que agendam na esfera pública a temática da responsabilidade social. (DELLAZZANA, 2011, p. 720).

Por fim, fica claro que existe um caminho no sentido de estudar a publicidade como formadora da agenda pública: 
[...] concentrada ou plural, antidemocrática ou libertária, a comunicação cada vez mais constrói e reconstrói a agenda e o discurso de nossa sociedade. Seja no nosso cotidiano ou nas decisões sobre o futuro da Nação. Seja no nosso bairro ou no planeta todo. Nossa conversa na rua sobre a mesma notícia que vimos em diferentes jornais, a roupa que usamos porque está na moda (ou na mídia), nossa intimidade com atores e apresentadores [...]. Tudo isso sofre influência e influencia os conteúdos e as mensagens que estão na mídia nossa de cada dia. (FNDC, 2008, p. 31).

Logo, a partir deste levantamento, concluiu-se que os diversos tipos de agendamento possíveis, já relatados em estudos anteriores, concebidos a partir da teoria do agendamento de McCombs e Shaw (1972), são um caminho possível no sentido de pesquisar e quiçá comprovar que as marcas corporativas, por meio de seus valores representados na publicidade, podem estar na agenda pública simplesmente por sua expressão e representação social, seus vínculos com os públicos e por causas que representam significativamente no cotidiano do consumo midiatizado.

Deve-se pontuar que este artigo se insere em uma visão contemporânea da comunicação como campo interdisciplinar em diálogo sincrônico com outras áreas do conhecimento, entretanto conservando a integridade de seu objeto e seu corpus dentro do campo da Comunicação, ou seja, a pesquisa se abre para referências de outros campos, interfaces e interferências, mantendo-se fidedigna à problemática da comunicação.

Nesta perspectiva, o que se pretende trazer à luz do debate sobre as marcas corporativas como passíveis de serem notícia é o evidente aspecto publicizador destes dispositivos, levando-se em conta que suas expressões se manifestam como práticas comunicativas de publicidade, propaganda e relações públicas, as quais são fundamentais neste processo para a possibilidade do agendamento de temas e valores na sociedade.

\section{Considerações Finais}

Os principais problemas encontrados para realizar o levantamento, e que se verificou de forma mais acentuada nos artigos nacionais, são a falta de assertividade e relação direta entre o conteúdo, os resumos e as palavras-chave. Diferente dos artigos internacionais que chegam a parecer repetitivos, pois nota-se um padrão que segue uma lógica que parte de identificar a teoria, o método, as temáticas principais e, se houver, as mídias a serem estudadas. Portanto, os meta-dados para indexação são mais claros no material do exterior e o material brasileiro não aponta para essa escolha mais precisa.

Outro ponto relevante é a fragilidade na apresentação da metodologia, pois quase a maioria dos artigos foca na descrição da pesquisa aplicada, onde deveria explicar a metodologia para depois descrever a sua aplicação. 
Inúmeros artigos que abordam a agenda (contexto de agenda dos meios e/ou agenda pública) e que falam de publicidade e marcas corporativas, apenas situam essas duas expressões como elementos secundários ou terciários do real sentido do texto, muitas vezes aparecendo somente uma vez ou apenas nas referências. Esses autores propõem a temática, mas, de fato, não a desenvolvem no decorrer de seu texto, incluindo pequenas menções ao agendamento e ao Agenda-Setting sem aprofundamentos.

Apesar de nos últimos 12 anos a produção sobre o assunto ainda ser tímida, o Brasil vem se destacando no cenário internacional na produção no segmento da publicidade, porém, necessitando publicar mais em língua estrangeira.

Quanto a influência da publicidade de marcas, inclusive corporativas, na formação da agenda, alguns artigos fazem considerações a esse respeito e, apesar de aporte teórico consistente, não há comprovação factual. Porém, existe um consenso, mesmo que este não seja resultado de um estudo direto, de que a publicidade de marcas de produtos ou de corporações pode ser responsável por agendar, principalmente se estas estiverem baseadas nos valores que essas marcas representam, seja reforçando ou se contrapondo aos valores sociais existentes.

Vale a ressalva que apenas dois artigos tratam efetivamente da influência da publicidade de marcas corporativas na agenda pública, o primeiro publicado no Intercom como trabalho de graduação (SENO OZAWA; BARROS FILHO, 2008) e o segundo publicado nos Anais do Pró-Pesq PP 2018 (ZIMMERMANN; MEIRA, 2018), o que aponta para o fato de que a publicidade tem espaço para se debruçar sobre esta perspectiva de objeto na pesquisa em comunicação, frente às possibilidades oferecidas na abordagem do agenda setting.

Ainda sobre a publicidade de marcas corporativas, é perceptível o crescimento do interesse em relação ao tema, quanto a sua pesquisa. Nota-se uma produção relevante em interface com as pesquisas de relações públicas. Já no que diz respeito a publicidade de marcas corporativas e sua relação com opinião pública e agenda-setting, destaca-se uma tendência a traçar o paralelo com foco no digital e ainda com a relação dos valores das organizações e seu diálogo com os valores sociais.

Outro aspecto relevante identificado nos artigos estudados é que a Teoria do AgendaSetting geralmente está associada a outras perspectivas teóricas, sugerindo um encadeamento das mesmas, como por exemplo Newsmaking, Espiral do Silêncio, Gatekepping e Gatewatching, Framing e Efeito de Priming, Knowledge Gap, entre outras.

Coelho (2005), na nota de abertura da Revista Comunicação e Sociedade de Portugal, ao mapear as teorias da comunicação, aponta que existe a possibilidade de os estudos ulteriores relacionarem a publicidade e propaganda ao agendamento de temas pela sociedade, principalmente as relacionadas às ações sociais.

Por fim, a pesquisa demonstrou que ainda não há nenhum estudo científico aprofundado, seja com pesquisa aplicada, quantitativa ou qualitativa, experimentos ou 
com comprovação teórica que possa validar a ideia da influência da publicidade de marcas corporativas na formação da agenda pública, apontando para um caminho de pesquisa ainda inexplorado, que é necessário.

O resultado a que se chega após a trajetória desses levantamentos sistemáticos longitudinais foi que também se faz necessário um aprofundamento no levantamento de tendências, no âmbito internacional, no que tange ao estudo do Agenda-Setting. E, posteriormente, abarcar essa temática para uma pesquisa mais aprofundada que possa realmente estabelecer se há relação entre a publicidade de marcas corporativas e a formação da agenda pública. As potencialidades dessas relações estão sinalizadas nos resultados, mas o tema pode ser trabalhado com efetiva profundidade.

Concomitantemente, verificou-se que há senso comum a alguns segmentos de pesquisa de que a publicidade efetivamente interfere na agenda pública, porém, sem aportes de pesquisas concretas e comprobatórias, o que torna a pesquisa factual dessa temática inédita e sugere avanços na perspectiva de continuidade dos estudos e pesquisas sobre o tema.

\section{Referências}

ALBALAWI, Y.; SIXSMITH, J. Agenda Setting for Health Promotion: Exploring an Adapted Model for the Social Media Era. JMIR Public Health Surveill. National University of Ireland Galway, Galway, Ireland, v. 1, p. 1-17, nov. 2015.

ALP, H. Political Advertising and Propaganda Within Spiral of Silence-Agenda Setting Theory. Journalism \& Mass Communication Quarterly. SAGE Publications in Newbury Park, California, v. 6, n. 1, p. 12-18, jan. 2016.

BARROS FILHO, C. de. Ética na Comunicação - da informação ao receptor. 4a. ed. São Paulo: Summus, 2003.

BOYLE, T. P. Intracampaign and intercandidate issue agenda-setting during the 2008 presidential campaign. In: 13TH INTERNATIONAL PUBLIC RELATIONS RESEARCH CONFERENCE. Coral Gables, Florida: University of Miami, p. 80-93, 2010. Anais [...].

CERVO, A. L.; BERVIAN, P. A. Metodologia científica. 5a. ed. São Paulo: Prentice Hall, 2002.

COELHO, Z. P. Nota de abertura. Revista Comunicação e Sociedade. Universidade do Minho. Minho, Portugal: Campo das Letras, v. 8, p. 7-11, 2005.

COVALESKI, R. et al. Divisão Temática Publicidade e Propaganda do Congresso Intercom: um estudo bibliométrico de 2001 a 2016. In: 40 CONGRESSO BRASILEIRO DE CIÊNCIAS DA COMUNICAÇÃO. Curitiba - PR: Intercom - Sociedade Brasileira de Estudos Interdisciplinares da Comunicação. - 04 a 09/09/2017. Disponível em: http://portalintercom.org.br/anais/nacional2017/resumos/R12-2559-1.pdf. Acesso em: 20 jan. 2018. Anais [...].

DA VIÁ, S. C. Opinião Pública - Técnicas de formação e problemas de controle. São Paulo: Loyola, 1983. DELLAZZANA, A. L. Accountability da publicidade e responsabilidade social. In: II PRÓ-PESQ PP ENCONTRO NACIONAL DE PESQUISADORES EM PUBLICIDADE E PROPAGANDA, São Paulo: ABP2/ECA-USP, 2011. Disponível em: https://www.abp2.org/e-books. Acesso em: 13 fev. 2017. Anais [...]. 
EL FARO, O; CARRASCOZA, J. L. A. O anúncio pautado pela imprensa: um estudo da relação entre a hipótese do agenda-setting e a criação de anúncios de oportunidade. Cadernos de Comunicação da Universidade Federal de Santa Maria - UFSM. Santa Maria: UFSM, v. 19, n. 2, p. 109-125, 2015. Disponível em: https:// periodicos.ufsm.br/ccomunicacao/article/view/20122. Acesso em: 1 mar. 2017.

ERNESTO, A. K. M. Consumo e agendamento: uma análise de 'Maysa Quando Fala o Coração'. Mossoró. 72 p., [Monografia de Graduação]. Comunicação Social - habilitação em Publicidade e Propaganda. Mossoró: UFRN, 2010.

ESROCK, S. L; LEICHTY, G. B. Social responsibility and corporate web pages: Self-presentation or agendasetting?. Public Relations Review. Elsevier Inc. Knoxville, Tennessee, USA/Amsterdam, Netherlands, v. 24, n. 3, p. 305-319, sep./oct./nov. 1998.

FÓRUM NACIONAL PELA DEMOCRATIZAÇÃO DA COMUNICAÇÃO - FNDC. Democratização da Comunicação: Como domar essa tal de mídia?. - Cartilha 1a. ed. Brasília-DF: FNDC, p. 31, 2008.

GUO, L. The Application of Social Network Analysis in Agenda Setting Research: A Methodological Exploration. Journal of Broadcasting \& Electronic Media. Taylor \& Francis Group - Milton Park, Abingdon-on-Thames, Oxfordshire United Kingdom, v. 56, n. 4, p. 616-631, 12 dec. 2012.

HABERMAS, J. Mudança estrutural da esfera pública: investigações quanto a uma categoria da sociedade burguesa. Rio de Janeiro: Tempo Brasileiro, 1984.

HAZAPARU, M. A. Agendamento em publicidade: compreender os dilemas éticos de um ponto de vista comunicativo. Comunicação e Sociedade. Braga: Universidade do Minho, v. 25, n. 1, p. 311-327, 2014.

KANEVA, N. Nation Branding: Toward an agenda for critical research. International Journal of Communication. University of Southern California USC Annenberg, Los Angeles, CA, USA, v. 5, p. 117141, 2011.

KIM, K. et al. Trends in Advertising Research: A Longitudinal Analysis of Leading Advertising, Marketing, and Communication Journals, 1980 to 2010. Journal of Advertising. Routledge Taylor \& Francis, Bellair Bluffs, Florida, USA, v. 43, n. 3, p. 296-316, 2014.

KIM, Y. et al. First and Second Levels of Intermedia Agenda Setting: Political Advertising, Newspapers, and Twitter During the 2012 U.S. Presidential Election. International Journal of Communication. University of Southern California USC Annenberg, Los Angeles, CA, USA, v. 10, p. 4550-4569, 2016.

LEITE, F. As Circulações de Sentido da Publicidade Contraintuitiva frente à Ameaça dos Estereótipos. In: III PRÓ-PESQ PP - ENCONTRO NACIONAL DE PESQUISADORES EM PUBLICIDADE E PROPAGANDA. São Paulo: 2012, p. 650. Disponível em: https://www.abp2.org/e-books. Acesso em: 25 fev. 2017. Anais [...].

LIPPMANN, W. Opinião Pública. Trad. Jacques A. Wainberg. 2a. ed. - Petrópolis: 2010.

MCCOMBS, M.; SHAW, D. The Agenda Setting function of mass media. Public Opinion Quarterly. New York, v. 36, n. 2, 1972. Disponível em: https://www.jstor.org/stable/2747787?origin=JSTOR-pdf\&seq=1. Acesso em: 5 jan. 2017.

MOTTA, B; BATISTA, L. L. Gatekeeping e gatewatching: filtros e alertas que ajudam no processo de escolha dos novos consumidores. In: II CONGRESSO MUNDIAL DE COMUNICAÇÃO IBERO-AMERICANA. Comunicação Ibero americana: os desafios da Internacionalização. Universidade Minho: CECS - Centro de Estudos de Comunicação e Sociedade, Braga, Portugal. Livro de Atas do II Congresso Mundial de Comunicação Ibero-americana, v. II, p. 3098-3106, 2014.

MYERS, D. Psicologia. 9a. ed. São Paulo: Editora: LTC, 2012. 
NOBRE, A. C.; EDE, F. V. Anticipated moments: temporal structure in attention. Nature Reviews Neuroscience. London: Macmillan Publishers Limited, v. 19, n. 1, p. 34-48, dec. 2017.

RAJULTON, F. The Fundamentals of Longitudinal Research: An Overview. Special Issue On Longitudinal Methodology. Canadian Studies in Population: Alberta, v. 28, n. 2, p. 169-185, 2001.

RIBEIRO, E.; MIESSVA, L. Rumo ao futuro. Anuário da Comunicação Corporativa 2016. São Paulo: Mega Brasil Comunicação, 2016, 200 p.

RICHARDSON, R. J. et al. Pesquisa social: métodos e técnicas. 3a. ed. rev. ampl. São Paulo: Atlas, 2007.

ROGERS, E; DEARING, J. Agenda-setting research: Where has it been, where is it going?. Communication Yearbook 11, Newbury Park, CA: Sage, v. 11, n. 1, p. 555-93, 1988.

SAMPAIO, R. F. MANCINI, M. C. Estudos de Revisão Sistemática: um guia para síntese criteriosa da evidência científica [Online]. Revista Brasileira de Fisioterapia. v. 11, n. 1. São Carlos, jan./fev. 2007. Disponível em: http://www.scielo.br/scielo.php?script=sci_arttext\&pid=S1413-35552007000100013. Acesso em: 11 abr. 2018.

SANTAELlA, L. Roteiro de projeto. [Online]. PEPG em Tecnologias da Inteligência e Design Digital da PUC-SP. PUC/SP: São Paulo, 2014. Disponível em: http://www.pucsp.br/sites/default/files/download/ posgraduacao/programas/tidd/roteiro_projeto_timbrado.pdf. Acesso em: 3 abr. 2017.

SENO OZAWA, J. V.; BARROS FILHO, C. de. Definição de valor, publicidade e a hipótese de agenda setting: uma análise dos recursos discursivos empregados no agendamento da publicidade. In: INTERCOM - XXXI CONGRESSO BRASILEIRO DE CIÊNCIAS DA COMUNICAÇÃO, Natal, 2008, p. 4. Anais [...].

STUMPF, I. R. C. Pesquisa bibliográfica. In: DUARTE, J.; BARROS, A. (Orgs.). Métodos e técnicas de pesquisa em comunicação. 2a. ed. São Paulo: Atlas, 2009.

TRAQUiNA, N. O Poder do Jornalismo: Análise e Textos da Teoria do Agendamento. 4a .ed. Coimbra, Minerva, 2000.

TRINDADE, E.; AUGUSTO JUNIOR, S. N. Aprofundamentos de Aspectos Conceituais entre Mediações Culturais e a Midiatização do Consumo Alimentar. In: IX PRÓ-PESQ PP - ENCONTRO DE PESQUISADORES EM PUBLICIDADE E PROPAGANDA. São Paulo: Pró-Pesq PP - CRP/ECA/USP, 2015. Anais [...]. Disponível em: https://www.abp2.org/e-books. Acesso em: 13 fev. 2017.

VILAR, M. L.; COVALESKI, R. L. Publicidade: transmissora de valores políticos e socioculturais. In: XXVI ENCONTRO DA COMPÓS. São Paulo SP: Compós, 2017, p. 5. Anais [...].

WATSON, J. Media Communication. An Introduction to Theory and Process, 3a. ed., New York: Palgrave Macmillan, 2008.

YALE, L; GILLY, M. C. Trends in Advertising Research: A Look at the Content of Marketing-Oriented Journals from 1976 to 1985. Journal of Advertising. v. 17, n. 1, p. 12-22, 1988.

ZIMMERMANN, D. D.; MEIRA, K. de M. A. Levantamento Sistemático Longitudinal dos Estudos Científicos sobre a Influência da Publicidade de Marcas Corporativas na Formação da Agenda. In: IX PRÓPESQ PP - ENCONTRO DE PESQUISADORES EM PUBLICIDADE E PROPAGANDA. São Paulo: CRP/ ECA/USP, 2018. Anais [...]. Disponível em: https://www.abp2.org/e-books. Acesso em: 13 jun. 2019.

\section{Eneus Trindade Barreto Filho}

Professor Associado da Escola de Comunicações e Artes (ECA), no Departamento de Relações Públicas, Propaganda e Turismo, curso de Publicidade e Propaganda, da Universidade de São 
Paulo (USP). Docente Permanente do PPGCOM (USP). Doutor em Ciências da Comunicação pela Universidade de São Paulo (2003). Possui pós-doutorado em Antropologia Visual pela Universidade Aberta de Portugal (2009). Bolsista de Produtividade em Pesquisa (PQ) - Nível 2 do CNPq. Pósdoutor e professor convidado - Chair Numeratie Publicitaire au CELSA Sorbonne Universités Paris - França (1S/2018). Co-líder do GESC3 - Grupo de Estudos Semióticos em Comunicação, Cultura e Consumo CNPq/USP. E-mail: eneustrindade@usp.br.

\section{Daniel Dubosselard Zimmermann}

Doutorando em Ciências da Comunicação na Escola de Comunicação e Artes da Universidade de São Paulo. Mestre em Comunicação e Mercado pela Faculdade Cásper Líbero (2006). Pesquisador do GESC3 - Grupo de Estudos Semióticos em Comunicação, Cultura e Consumo. Pesquisador do CECORP - Centro de Estudos de Comunicação Organizacional e Relações Públicas. Professor da graduação e vice-coordenador do curso de Relações Públicas da Faculdade Cásper Líbero. E-mail: ddzimmer@usp.br.

\section{Karla de Melo Alves Meira}

Mestranda em Ciências da Comunicação na Universidade de São Paulo - PPGCOM ECA/USP. Bolsista - nível Mestrado - pelo CNPq. Pesquisadora do GESC3 - Grupo de Estudos Semióticos em Comunicação, Cultura e Consumo. E-mail: meira.karla@usp.br.

Recebido em: 24.06.2020

Aprovado em: 28.01.2021

Este artigo é publicado em acesso aberto (Open Access) sob a licença Creative Commons Attribution Non-Commercial (CC-BY-NC), que permite uso, distribuição e reprodução em qualquer meio, sem restrições, desde que sem fins comerciais e que o trabalho original seja corretamente citado. 